\title{
Lignin-Degrading Enzymes From a Pathogenic Canker-Rot Fungus, Inonotus Obliquus Strain IO-B2 (NBRC 113408)
}

\section{Retno Agnestisia}

Tokyo University of Agriculture and Technology

Tomohiro Suzuki ( $\nabla$ suzukit@cc.utsunomiya-u.ac.jp )

Utsunomiya University

Akiko Ono

Utsunomiya University

Luna Nakamura

Utsunomiya University

Ikumi Nezu

Utsunomiya University

Yuki Tanaka

Utsunomiya University

Haruna Aiso

Shizuoka Professional University of Agriculture

Futoshi Ishiguri

Utsunomiya University

Shinso Yokota

Utsunomiya University

\section{Research Article}

Keywords: pathogenic, therapy, peroxidase, molecular

Posted Date: October 25th, 2021

DOI: https://doi.org/10.21203/rs.3.rs-964323/v1

License: (c) (1) This work is licensed under a Creative Commons Attribution 4.0 International License.

Read Full License 


\section{Abstract}

Inonotus obliquus is pathogenic fungus on living trees and has been widely used as a traditional medicine for cancer therapy. Although it has been reported that lignocellulose-degrading enzymes are involved in the early stage of host infection, the parasitic life cycle of this fungus has not been fully clarified. In the present study, we investigated the activities of lignin-degrading enzymes from I. obliquus and analyzed the degradation products. Our results revealed that I. obliquus is a pathogenic canker-rot fungus that does not produce lignin peroxidase (LiP), yet is capable of degrading the non-phenolic unit of lignin. The draft genome sequence of this fungus consisted of 21,203 predicted protein coding genes, of which 136 genes were estimated to be related to wood degradation. Furthermore, we found genes encoding putative versatile peroxidase (VP) and dye-decolorizing peroxidase (DyP), which are considered to be involved in the degradation of the non-phenolic unit of lignin. Thus, we cloned the cDNA encoding putative VP, referred as IO-Px, and characterized its molecular structure. From the above results, we suggested that: 1) IO-Px is a new member of MnP, and 2) the ability of I. obliquus to degrade non-phenolic lignin unit might arise from DyP properties.

\section{Introduction}

Inonotus obliquus (Fr.) Pilát, commonly known as "Chaga" in Russia and "Kabanoanatake" in Japan, is a member of white-rot fungi classified into the family Hymenochaetaceae (Fig. 1A). However, unlike other white-rot fungi, this fungus parasitizes living trees and forms sclerotia or canker-like bodies, called "Chaga" (Fig. 1B). These cankers gradually destroy the trunk, leading to tree damage and eventually death $^{1,2}$. The fungus is known to cause canker-rot disease on mostly birch (Betula spp.) trees ${ }^{1,2}$; therefore, I. obliquus is also often referred to as a pathogenic canker-rot fungus ${ }^{1}$. This pathogenic fungus is widely distributed in boreal to temperate forests and confined to cold habitats at latitudes of $45-50^{\circ} \mathrm{N}$, including North America, Finland, Poland, Russia, northeast China, and Japan ${ }^{3}$.

Several researchers reported that the parasitic life cycle of $I$. obliquus in living trees has unique features ${ }^{2,4}$. Basidiospores of this fungus penetrate the tree through wounds, grow into the wood, and form sclerotia (thick-walled black mycelia) after 10-15 years of parasitism ${ }^{2,4}$. In order to grow in living trees, I. obliquus degrades chemical components of the wood cell wall to obtain the primary carbon source nutrients required for growth during colonization ${ }^{1}$. This is accomplished by secreting lignocellulose-degrading enzymes, which are produced during fungal secondary metabolism in response to nutrient limitation. These enzymes are capable of degrading cellulose, hemicellulose, pectin, and lignin as components of the wood cell wall through hydrolytic and oxidative activities ${ }^{5}$. Since I. obliquus is a member of white-rot fungi, it potentially degrades all chemical components in the wood cell wall. This activity is considered to play a key role during the early infection stage of $I$. obliquus in colonizing and invading the heartwood of Japanese birch trees. 
Several studies have clarified that $I$. obliquus can degrade cellulose, hemicellulose, and lignin in the biomass of non-woody plants, such as corn straw ${ }^{6}$, wheat straw, rice straw, and sugarcane bagasse ${ }^{7}$. Xu et al. (2017) also examined the enzyme activities of I. obliquus in degrading cellulose, hemicellulose, and lignin in wheat straw, rice straw, and corn stover ${ }^{8}$. They found the enzyme activities of $\beta$-glucosidase, xylanase, and manganese peroxidase in $I$. obliquus $^{8}$. However, further data are required to fully understand the enzymatic systems of $I$. obliquus involved in degrading the chemical components of plant cell walls, especially in woody plants.

Lignin is the chemical component in wood cell walls that is most efficiently degraded by white-rot fungi in nature ${ }^{9}$. In light of this ability, white-rot fungi are considered to be suitable for biopulping ${ }^{9}$. Therefore, it is very important to investigate lignin-degrading enzyme activities of I. obliquus and analyze degradation products from lignin and lignin model compounds. Lignin-degrading enzymes of white-rot fungi are classified into lignin-modifying enzymes and lignin-degrading auxiliary enzymes ${ }^{10}$. Lignin-modifying enzymes are typically oxidative enzymes classified into laccases and heme-containing peroxidases ${ }^{10}$. Laccase (Lac; EC 1.10.3.2) is a copper-containing phenol oxidase that can directly oxidize the phenolic units of lignin using molecular oxygen $\left(\mathrm{O}_{2}\right)$ as an oxidizing agent ${ }^{5,10}$, and can also oxidize the nonphenolic units of lignin in the presence of a suitable mediator ${ }^{11}$. Heme-containing peroxidases can oxidize phenolic or non-phenolic units of lignin using hydrogen peroxide $\left(\mathrm{H}_{2} \mathrm{O}_{2}\right)$ as an oxidizing agent ${ }^{5}$. On the other hand, lignin-degrading auxiliary enzymes are known to provide $\mathrm{H}_{2} \mathrm{O}_{2}$ for heme-containing peroxidases to complete the lignin degradation process ${ }^{10}$.

Heme-containing peroxidases are highly attractive as biocatalysts compared to laccases because of their high redox potential ${ }^{12}$. Heme-containing peroxidases from white-rot fungi are classified into manganese peroxidase (MnP; EC 1.11.1.13), lignin peroxidase (LiP; EC 1.11.1.14), and versatile peroxidase (VP; EC 1.10.3.2 ${ }^{10}$. MnP is characterized by a Mn-binding site that can oxidize the phenolic units of lignin ${ }^{13}$. Unlike MnP, LiP is characterized by an invariant tryptophan (Trp) residue located on the enzyme surface $^{14}$. This residue participates in the long-range electron transfer (LRET) pathway to oxidize the nonphenolic units of lignin ${ }^{14}$. These structural features of both MnP and LiP are present in VP ${ }^{15,16}$. Due to these properties, VP has catalytic properties that are distinct from both enzymes, enabling it to oxidize both phenolic and non-phenolic units of lignin ${ }^{16}$. Thus, VP can be utilized as an exciting biocatalyst for biotechnology application, such as textile and pulp bleaching, production of biofuel, bioremediation of xenobiotic compounds, etc. ${ }^{17}$.

In recent years, genome sequencing technology and bioinformatics tools have been the most efficient methods capable of rapidly providing whole genome information at a molecular level for a fungus. The obtained genome information provides a database of relevant genes related to wood degradation ${ }^{18}$. To date, the genomes of many white-rot fungi have been sequenced, such as Phanerochaete chrysosporium $^{18}$, P. carnosa ${ }^{18}$, Heterobasidion irregulare ${ }^{19}{ }^{\text {, Ganoderma lucidum }}{ }^{20}$, Trametes versicolor ${ }^{21}$, Lentinula edodes, ${ }^{22}$ and $P$. eryngii ${ }^{23}$. Many genes related to wood degradation were identified in their 
genome resources. In addition, different types of genes involved in lignin degradation have also been characterized ${ }^{24}$. Molecular characterizations of MnP and LiP have also been conducted in many species using cDNA clone sequences, including Polyporales, Agaricales, and Corticiales basidiomycetes ${ }^{24-26}$. By contrast, complementary DNA (cDNA) from VP genes has been cloned and characterized in only a few species, such as $P$. eryngii ${ }^{15,16}, P$. sapidus ${ }^{27}$, Bjerkandera strain ${ }^{28}$, and $B$. adusta ${ }^{29}$. However, further detailed information on the structure of this enzyme is required to enable modulation of its catalytic and operational properties during lignin degradation.

In the present study, we investigated the activities of lignin-degrading enzymes from I. obliquus and analyzed the degradation products using a lignin model dimer. We also conducted genome sequencing and mined genes related to wood degradation. This information is expected to provide new insights into the enzymatic systems of $I$. obliquus involved in degrading wood chemical components, especially lignin. From the obtained results, we cloned one of the cDNAs encoding putative VP and characterized its structural features, which were used to clarify the role of this enzyme in lignin degradation. In addition, we also applied phylogenetic analysis to investigate the evolutionary relationships of this enzyme with other basidiomycete peroxidases.

\section{Results}

Lignin-degrading enzyme activities and degradation products. Table 1 shows that Lac and MnP activities, but not LiP activity, were found in a crude extract obtained from fungal mycelia grown in Kirk medium with the addition of veratryl alcohol and oxygen flashing. The activities of Lac and MnP were 0.102 and $0.992 \mathrm{fkat} / \mathrm{mg}$, respectively. Interestingly, according to the results of GC-MS analysis of the catabolites derived from degradation of the lignin model dimer (1-(4-ethoxy-3-methoxyphenyl)-2-(2,6dimethoxyphenoxy)-1,3-propanediol) by I. obliquus (Supplementary Fig. 1), this fungus was able to cleave the $\mathrm{O}_{-} \mathrm{C}_{4}$ linkage of the lignin model dimer to form derivative I (1-(4-ethoxy-3-

methoyphenyl)glycerol) (Fig. 2). Derivative I was then oxidized at the Ca position to form derivative II (1(4-ethocy-3-methoyphenyl)-2,3-dihydroxypropane-1-one) (Fig. 2). This indicates that I. obliquus has the ability to degrade non-phenolic units of lignin, even though LiP activity is absent.

Table 1

Specific activity of lignin-degrading enzymes in I. obliquus.

\begin{tabular}{|ll|}
\hline Type of enzyme & Specific activity (fkat/mg) \\
\hline Lac & 0.102 \\
\hline MnP & 0.992 \\
\hline LiP & 0.000 \\
\hline Note: Lac, laccase; MnP, manganese peroxidase; LiP, lignin peroxidase. \\
\hline
\end{tabular}

Genome features. The statistics of the assembled, predicted, and annotated genome of I. obliquus are summarized in Table 2. The genome of I. obliquus was successfully sequenced using a next-generation 
sequencing strategy on the Illumina MiSeq platform and assembled into 15,755 contigs with N50 length of 9,032 bp. The length of contigs ranged from $200 \mathrm{bp}$ to 199,051 bp with an average length of 2,694.8 bp. Overall, the I. obliquus genome generated $42.5 \mathrm{Mbp}$ nucleotides with $47.6 \% \mathrm{GC}$ content. This genome size is within the typical range size of genomes in basidiomycetes ${ }^{19-23,30}$, and somewhat similar with that of L. edodes (41.8 Mbp) ${ }^{22}$. L. edodes is a white rot fungus (order Agaricales in the phylum Basidiomycota) and is widely known as an edible mushroom due to its high nutrition and medicinal effect $^{22}$. Furthermore, genome assembly of $I$. obliquus contained two genes for rRNAs and 136 genes for tRNAs (Table 2). These 136 tRNAs were found to correspond to the full set of 20 amino acids. A total of 21,203 protein coding genes were detected from this genome assembly. The number of protein coding genes in the I. obliquus genome is within the range for fungi, around $11,000-20,000^{30}$.

Table 2

Assembly, prediction, and annotation statistics for the I. obliquus genome.

\section{Characteristic \\ Statistic}

Number of genome contigs

N50 length (bp)

Shortest contig length (bp)

Longest contig length (bp)

Average contig length (bp)

Total number of nucleotides in genomic contig (bp)

GC content (\%)

rRNA genes

tRNA genes

Number of protein coding genes

Number of genes annotated by nt database

Number of genes annotated by Swiss-prot database

Number of genes annotated by Pfam

Number of genes annotated by GO

Number of genes annotated by KEGG

Number of genes annotated by PHI-base

Note: N50 length, the minimum contig length needed to cover $50 \%$ of the genome; bp, base pair; GC, guanine-cytosine; tRNA, transfer RNA; rRNA, ribosomal RNA.

The predicted protein coding genes were further blasted in the non-redundant nucleotide (nt) database, Swiss-prot database, Pfam database, and Kyoto Encyclopedia of Genes and Genomes (KEGG) database.
15,755

9,032

200

199,051

$2,694.8$

$42,456,479$

47.6

2

136

21,203

8,280

4,188

16,190

11,450

5,277

1,621 
Among the 21,203 predicted protein coding genes, 8,280 and 4,188 genes had significant similarity to those documented in the nt and Swiss-prot databases, respectively (Table 2). The result of the Pfam search clarified that 16,190 genes have structural domains (Table 2 and Supplementary Fig. 2). This result revealed that the I. obliquus genome is enriched in three conserved domains, including protein kinase domain (PF00069.24; 464 genes), protein tyrosine kinase (PF07714.16; 390 genes), and the AAA ATPase domain (PF13191.5; 388 genes). Moreover, the predicted protein coding genes were also assigned to Gene ontology (GO) terms to gain functional information. A total of 11,450 genes were included in this annotation (Table 2). Among them, 7,936, 2,032, and 1,482 genes were mapped to molecular function (MF), biological process (BP), and cellular component (CC), respectively (Supplementary Fig. 3).

A total of 5,277 genes were documented in the KEGG database and were significantly included in the biosynthesis of secondary metabolites (map01110; 257 genes) (Supplementary Fig. 4). The result of KEGG pathway analysis indicated that several pathways in the biosynthesis of secondary metabolites are known to be related to the pathways for medicinal compound biosynthesis. This information confirms previous studies, which showed that $I$. obliquus is used as a traditional medicine in West Siberia to treat several diseases, such as heart, liver, and stomach diseases, tuberculosis, and diabetes ${ }^{31}$. In addition, the pathway of lanosterol biosynthesis was also found in the present study (Supplementary Table 1), which is associated with six genes of terpenoid backbone biosynthesis (map00900; Supplementary Fig. 5A) and three genes of steroid biosynthesis (map00100; Supplementary Fig. 5B). The pathways of terpenoid backbone biosynthesis seem to be distributed only in the mevalonate (MVA) pathway. A similar result was also found in other basidiomycetes such as $G$. lucidum ${ }^{20}$. The putative pathway of lanosterol biosynthesis is shown in Supplementary Fig. 5C. Lanosterol is a class of chemical compounds that have beneficial properties for human health, such as an antitumor effect ${ }^{32}$. On the other hand, lanosterol is also considered as an important intermediate in the synthesis of inotodiol and trametenolic acid through hydroxylation and oxidation reactions ${ }^{32}$. These chemical compounds are present in 1 . obliquus and are known to have anti-inflammatory, anticancer, and antitumor effects ${ }^{3,32}$.

Genes related to wood degradation. From the functional annotation results, a total of 134 genes were detected in the I. obliquus genome that are potentially involved in the degradation of wood chemical components (Table 3). These genes were typical of white-rot fungi, with the highest number of genes for lignin degradation observed. These genes consist of 36 candidate cellulase genes, 35 candidate hemicellulase genes, 16 candidate pectinase genes, 37 candidate lignin modifying enzyme genes, and 10 candidate lignin degrading auxiliary enzyme genes, respectively. Annotation of these genes in nt, Swissprot, Pfam, GO, and KEGG databases is shown in Supplementary Table 2. All findings indicate that $I$. obliquus has enzyme encoding genes that can potentially target all chemical components of wood cell walls, including cellulose, hemicellulose, pectin, and lignin, reflecting its ability as a white-rot fungus. Possession of the huge variety of enzyme encoding genes in this fungus may be related to its parasitic nature, where its survival depends on degraded wood chemical components in the host as the primary 
carbon source of nutrients for growth during colonization, as observed for the pathogenic white-rot fungus $H$. irregulare ${ }^{19,33}$. 
Table 3

Candidate genes involved in degradation of wood chemical components by 1 . obliquus.

\begin{tabular}{|c|c|c|}
\hline Class & Putative enzyme & Number of genes \\
\hline \multirow[t]{5}{*}{ Cellulase } & Endoglucanase & 9 \\
\hline & Exoglucanase & 9 \\
\hline & $\beta$-Glucanase & 15 \\
\hline & Cellobiose dehydrogenase & 3 \\
\hline & Total & 36 \\
\hline \multirow[t]{13}{*}{ Hemicellulase } & $\beta$-Xylosidase & 6 \\
\hline & Endo-1,4- $\beta$-xylanase & 7 \\
\hline & 4-O-Methyl-glucuronoyl methylesterase & 1 \\
\hline & Acetylxylan esterase & 2 \\
\hline & a-Xylosidase & 2 \\
\hline & a-Fucosidase & 2 \\
\hline & $\beta$-Mannosidase & 6 \\
\hline & Endo- $\beta$-mannanase & 1 \\
\hline & a-Galactosidase & 3 \\
\hline & a-L-Arabinofuranosidase & 3 \\
\hline & Arabinogalactan endo- $\beta-1,4$-galactanase & 1 \\
\hline & Feruloyl esterase & 1 \\
\hline & Total & 35 \\
\hline \multirow[t]{9}{*}{ Pectinase } & Pectinesterase & 1 \\
\hline & Pectate lyase & 4 \\
\hline & Polygalacturonase & 1 \\
\hline & Endopolygalacturonase & 2 \\
\hline & Exoplygalacturonase & 4 \\
\hline & a-L-Rhamnosidase & 2 \\
\hline & Rhamnogalacturonan acetylesterase & 1 \\
\hline & Arabinan endo-1,5-a-L-arabinosidase & 1 \\
\hline & Total & 16 \\
\hline
\end{tabular}




\begin{tabular}{|lll|}
\hline Class & Putative enzyme & Number of genes \\
\hline Lignin-modifying enzyme & Laccase & 14 \\
\cline { 2 - 3 } & Manganese peroxidase & 14 \\
\cline { 2 - 3 } & Versatile peroxidase & 7 \\
\cline { 2 - 3 } & Dye-decolorizing peroxidase & 2 \\
\hline Lignin-degrading auxiliary enzyme & Total & 37 \\
& Glucose oxidase & 3 \\
\cline { 2 - 3 } & Alcohol oxidase & 2 \\
\cline { 2 - 3 } & Aldehyde oxidase & 5 \\
\hline Total & Total & 10 \\
\hline
\end{tabular}

As found in the above results, I. obliquus has the highest number of genes for lignin degradation. A total of 47 genes were related to lignin degradation and were categorized into two main classes (Table 3 ). The first contains 39 candidate lignin modifying enzyme genes consisting of 14 candidate lac genes, 14 candidate $M n P$ genes, seven candidate $V P$ genes, and two candidate dye-decolorizing peroxidase (DyP) genes. The second contains 10 candidate lignin degrading auxiliary enzyme genes consisting of three candidate glucose oxidase genes, two candidate alcohol oxidase genes, and five candidate aldehyde oxidase genes. These results show that Lac is an enzyme with the highest number of genes present in the I. obliquus genome. This enzyme generally has a larger number of genes than heme-containing peroxidases in white-rot fungi, except for $P$. chrysosporium ${ }^{20-22,33}$. Hence, it is considered that laccase plays an important role in lignin degradation in I. obliquus. In plant pathogenic fungi, laccase also plays an important role in detoxification of phenolic compounds involved in plant host defense ${ }^{33}$ and melanin production ${ }^{34}$. Melanin is a natural pigment, which is also produced by 1 . obliquus to protect its cells in sclerotia ${ }^{4}$.

The second highest number of genes in the $\mathrm{l}$. obliquus genome are MnP genes. MnP is a member of heme-containing peroxidases that can oxidize the phenolic units of lignin and appears to have the largest number of genes compared to other heme-containing peroxidases in white-rot fungi like $L$. edodes ${ }^{22}$. A consistent result for LiP was found in this study, where a gene encoding LiP was not detected in this fungal genome. Interestingly, VP was detected in the fungal genome, although the number of genes is lower than that of other putative enzymes. Moreover, genes encoding DyP were also found in the $I$. obliquus genome. Even though the ligninolytic activity of this enzyme is prominent in bacteria ${ }^{10}$, it is also detected in some fungi such as Termitomyces albuminosus ${ }^{35}$, and Auricularia auricula-judae ${ }^{36}$. In A. auricula-judae, DyP is known to be capable of degrading non-phenolic lignin units. This is because this enzyme has tyrosine (Tyr337) and tryptophan (Trp377) residues that can be used to participate in long- 
range electron transfer similar to $\mathrm{LiP}^{36,37}$. These residues were also present in the deduced amino acid sequence of DyP genes in I. obliquus. Therefore, DyP of I. obliquus may also have the ability to degrade non-phenolic lignin units (Supplementary Fig. 6).

As mentioned above, heme-containing peroxidases cannot function without the presence of the second class of lignin degrading enzymes, i.e., lignin degrading auxiliary enzymes ${ }^{10}$. Genes encoding glucose oxidase, alcohol oxidase, and aldehyde oxidase were detected in the l. obliquus genome. These enzymes have a role in providing the $\mathrm{H}_{2} \mathrm{O}_{2}$ necessary for heme-containing peroxidase activities to accomplish the lignin degradation process ${ }^{10}$. In addition, the enzymes are also known to potentially support the Fenton reaction through the generation of extracellular $\mathrm{H}_{2} \mathrm{O}_{2}$ together with cellobiose dehydrogenase, which is included in the cellulase class of enzymes ${ }^{38}$. These facts indicate that oxidase, peroxidase, and free radical generation are considered to be key components for lignin degradation by 1 . obliquus, and suggest that the lignin degrading enzymes of $I$. obliquus potentially target the entire lignin molecule, including phenolic and non-phenolic moieties.

Molecular characterization of IO-Px. As is well known, VP is a superior among other lignin-degrading enzymes and enables the oxidization of all lignin units. Therefore, molecular characterization of VP from 1. obliquus is needed to clarify its role in the degradation of non-phenolic lignin unit by this fungus. One of the seven candidate VP genes was successfully cloned in the vector PMD20-T using the TA cloning method, referred as $10-P x$. This gene contained 1,078 nucleotides encoding 347 deduced amino acids. Additionally, SignalP analysis indicated the presence of a 20 amino acid signal peptide (Fig. 3). These results suggest that IO-Px is a typical secreted protein, which is consistent with the fact that it is an extracellular fungal enzyme.

A comparison of the deduced amino acid sequence between IO-Px with other deduced amino acid sequences of basidiomycete peroxidases is shown in Fig. 3. The result showed that IO-Px has conserved heme pocket residues, i.e., Arg43, Phe46, His47, His172, Phe189, and Asp219. It is known that the heme (prosthetic group) of heme-containing peroxidases is involved in $\mathrm{H}_{2} \mathrm{O}_{2}$ reaction. To investigate the steric orientation of each amino acid and to clarify the catalytic properties of IO-Px, molecular modeling of IOPx protein was performed by sequence homology using a model server and built using the templates from PDB entries, 1MnP, 2BOQ, and Lga1 for MnP (Fig. 4A), VP (Fig. 4B), and LiP (Fig. 4C), respectively. Fig. 4D shows that His47 and His172 were found as the distal and proximal histidine residues of heme, respectively. Meanwhile, Arg43, Phe46, Phe186, and Asp219 are the residues near the distal and proximal histidines (distal pocket). Pease et al. (1989) reported that heme-containing peroxidases have two histidine residues that are proposed to be essential for their activity ${ }^{39}$. The proximal histidine residue is predicted to be the axial ligand of the heme iron, while the distal histidine residue participates in peroxide cleavage ${ }^{39}$. The obtained result revealed that IO-Px has the residues essential for peroxidase activity. In addition, Fig. 3 also shows that the deduced heme pocket residues of IO-Px are conserved among other genes encoding typical MnP (PC-MnP1), typical VP (B-VP, PE-VPL1, PE-VPL2, PE-VPL3, PE-VPS1, and 
PSA-VP), putative VP (PO-MnP1, PO-MnP2, and PP-MnP5), and typical LiP (PC-LiPA). These results demonstrated that IO-Px is a member of heme-containing peroxidases.

On the other hand, IO-Px also has three acidic residues located in front of the internal heme propionate, i.e., Glu36, Glu40, and Asp178 (Figs. 3 and 4A, 4B). These residues are important to the formation of a Mn-binding site ${ }^{15,26}$. As is well known, the Mn-binding site is stabilized by three acidic residues (tricarboxylates of two glutamate (Glu) and one aspartate (Asp) residues), one internal heme propionate, and two water molecules in an octahedral molecular geometry ${ }^{13,17}$. At the $\mathrm{Mn}$-binding site, $\mathrm{Mn}^{2+}$ is oxidized into $\mathrm{Mn}^{3+}$, where it is chelated by organic acids secreted by fungi, such as oxalate, glyoxalate, and lactate ${ }^{17}$. The resultant $\mathrm{Mn}^{3+}$-organic acid complex acts as a diffusible redox mediator to oxidize the phenolic units of lignin ${ }^{5}$. The identified acidic residues in IO-Px also showed homology with typical MnP from P. chrysosporium (PC-MnP1) and VP from P. eryngii (PE-VPL1, PE-VPL2, and PE-VPL3). Therefore, the obtained results indicate that IO-Px has catalytic properties analogous to MnP. Unexpectedly, IO-Px did not have an exposed tryptophan residue (Typ171 for LiP and Typ164 for VP, Fig. 3). This residue is a characteristic component for LiP and is located on the protein surface ${ }^{15,26}$. The absence of this residue in IO-Px indicates that the enzyme does not exhibit LiP catalytic activity. Furthermore, phylogenetic analysis was performed using 57 deduced amino acid sequences of basidiomycete peroxidases including IO-Px in order to investigate evolutionary relationships between IO-Px and other heme-containing peroxidases (Fig. 5). The result showed that IO-Px was located in the clade of VP of Fomitiporia mediterranea and MnPs from three different species, i.e. Pyrrhoderma noxium, F. mediterranea and Sanghuangporus baumii.

\section{Discussion}

As described above, I. obliquus is a pathogenic white-rot fungus that is parasitic on living trees. During parasitization of host trees, this fungus acquires nutrients for growth by degrading chemical components in the wood cell wall, including cellulose, hemicellulose, pectin, and lignin. Among these chemical components, lignin is the most efficiently degraded by this fungus. Here, we investigated lignin-degrading enzyme activities of I. obliquus. The lignin-degrading enzymes assayed were Lac, MnP, and LiP. Based on the results, we identified Lac and MnP activities in I. obliquus grown on Kirk medium, whereas LiP was not detected (Table 1). The absence of LiP activity in this fungus might be caused by unsuitable medium or cultivation conditions. Another possible reason is that this fungus represents pathogenic white-rot fungi that do not produce LiP, like L. edodes. Unexpectedly, I. obliquus exhibited the ability to degrade nonphenolic unit of lignin, namely the model dimer, 1-(4-ethoxy-3-methoxyphenyl)-2-(2,6-

dimethoxyphenoxy)-1,3-propanediol (Fig. 2). Interestingly, these catabolic activities cannot be catalyzed by Lac and MnP without the existence of mediators, but can be catalyzed by LiP. However, LiP activity was not detected in this fungus. These results indicate that the enzymatic system of $I$. obliquus involved in the degradation of non-phenolic lignin requires clarification.

We sequenced the genome of $I$. obliquus and investigated genes related to wood degradation. From this genome resource, we found 49 lignin-degradation-related genes (Table 3). Consistent with the enzymatic 
activity results above, we did not find any genes encoding LiP. This reinforces the suggestion that $I$. obliquus is a typical white-rot fungus that does not produce LiP. In contrast, genes encoding VP were found in the I. obliquus genome. The presence of these genes can replace the function of LiP, because VP has catalytic properties analogous to those of LiP to oxidize non-phenolic units of lignin ${ }^{16-18}$. In this context, we successfully cloned one of the seven genes encoding putative VP(IO-PX) (Fig. 3). The obtained deduced amino acid sequence from the $1 O-P x$ gene was then characterized to investigate its catalytic properties in clarifying the role of this enzyme in the degradation of non-phenolic unit of lignin. Unexpectedly, the results show that IO-Px is a member of the heme-containing peroxidases that show analogous catalytic properties to those of MnP, but not LiP (Fig. 4).

Furthermore, the phylogenetic analysis conducted in this study revealed that IO-Px was located in the clade of VP of F. mediterranea and MnPs from three different species, i.e. P. noxium, F. mediterranea and $S$. baumii. In this clade, IO-Px and VP of $F$. mediterranea are clearly separated, but it seems to be closely related to the MnPs from P. noxium, F. mediterranea and $S$. baumii which belong to the same family of Hymenochaetaceae and lack the tryptophan residue (Fig. 5; Supplementary Fig. 7). Morgenstern et al. (2010) reported that the presence of the Mn-binding residues and the lack of the exposed tryptophan residue characterize the enzymes as MnPs. In addition, Morgenstern et al. (2010) also revealed that the position of the tryptophan residue that characterize LiPs and VPs is usually occupied by an alanine or serine residue in MnPs. These characteristics are similar to that of IO-Px exposed to Mn-binding residues, but lacked the tryptophan residue which its presence was replaced by alanine residue (Fig. 5; Supplementary Fig. 7). Therefore, we suggested that IO-Px that previously predicted as VP based on similarities to homologous VPs in Swiss-prot database of amino acid sequences is a new member of MnPs after being confirmed by its cDNA sequence. Certainly, these results cannot be used to fully understand the enzymatic systems of I. obliquus involved in degradation of non-phenolic lignin unit. Consequently, we suggested that analysis of the six putative VP genes that have not been cloned in the present study are required to confirm the presence of VP in I. obliquus and their involvement in degrading non-phenolic unit of lignin. On the other hand, genes encoding DyP were also present in the I. obliquus genome (Table 3 and Supplementary Table 2). This is also known as a lignin-degrading enzyme capable of degrading non-phenolic lignin units, although its physiological role remains unclear. If IO-Px is unrelated to VP, the ability of $I$. obliquus to degrade non-phenolic lignin unit might arise from DyP properties. However, further crystallographic, kinetic, and spectroscopic studies of these enzymes are required to confirm all of the possibilities.

\section{Methods}

Fungal strain. Inonotus obliquus strain IO-B2 (NBRC 113408) from Forest Resource Biology, Forest Resource Science, Division of Environmental Resources, Graduate School of Agriculture, Hokkaido University, Japan, was used in this study. This fungus was pre-cultured on $39 \mathrm{~g} / \mathrm{L}(\mathrm{w} / \mathrm{v})$ potato-dextroseagar (PDA; Becton, Dickinson and Company, Sparks, MD, USA) medium in a 9-cm diameter Petri dish at $25 \pm 2^{\circ} \mathrm{C}$ in the dark. 
Enzyme activity assays. The actively growing I. obliquus mycelia on PDA medium were collected and inoculated to $20 \mathrm{~mL}$ of Kirk medium ${ }^{40}$ in an Erlenmeyer flask $(300 \mathrm{~mL})$ for 3 weeks at $26 \pm 2^{\circ} \mathrm{C}$ under static conditions in the dark. Then, $300 \mu \mathrm{L}$ of veratryl alcohol (Tokyo Chemical Industry Co. Ltd., Tokyo, Japan; $100 \mathrm{mM}$ ) in dimethylformamide (Kanto Chemical Co. Inc., Tokyo, Japan) was added to the medium, and oxygen was flashed for $30 \mathrm{~s}$. After 2 days of treatment, the culture solution was collected through Miracloth (Calbiochem, San Diego, CA, USA). The filtrate was centrifuged at 9,810 $\mathrm{g} g$ for $10 \mathrm{~min}$ at $4^{\circ} \mathrm{C}$. The collected supernatant was transferred into dialysis tubes $(27$ inch $\times 32$ feet, Sanko Pure Chemical, Ltd., Gifu, Japan) and dehydrated with polyethylene glycol 20,000 (Wako Pure Chemical Co., Osaka, Japan) for $3 \mathrm{~h}$ at $7^{\circ} \mathrm{C}$. The concentrated solution in dialysis tubes was dialyzed against $20 \mathrm{mM}$ succinate buffer $(\mathrm{pH} 6.5)$ at $7^{\circ} \mathrm{C}$ overnight. The obtained crude enzyme solution was subjected to lignindegrading enzyme assays. Enzyme activities of Lac, MnP, and LiP were determined using previously reported methods ${ }^{41-43}$. The experiments were performed in triplicate.

Degradation product analysis. The fungal mycelia were inoculated under the same conditions described in section of enzyme activity essays. After 3 weeks of culture, $100 \mu \mathrm{L}$ of a lignin model dimer (1-(4-ethoxy3-methoxyphenyl)-2-(2,6-dimethoxyphenoxy)-1,3-propanediol ${ }^{44}$ at a concentration of $0.02 \mathrm{mg} / \mu \mathrm{L}$ in dimethylformamide (Kanto Chemical Co. Inc.) was added to the medium, and oxygen was flashed for 30 $\mathrm{s}$. The culture solution was then collected through Miracloth after 2 days of treatment. The catabolites in the culture solution were extracted with $15 \mathrm{~mL}$ of ethyl acetate (Wako Pure Chemical Co.). The ethyl acetate solution was then dehydrated with sodium sulfate anhydride (Wako Pure Chemical Co.). The solvent was evaporated off using a rotary evaporator (EYELA N-1100; EYELA Co., Ltd., Tokyo, Japan) and the extracts were dried in vacuo. The extracts were acetylated with $2 \mathrm{~mL}$ of pyridine (Wako Pure Chemical Co.) and $2 \mathrm{~mL}$ of acetic anhydride (Wako Pure Chemical Co.) at room temperature in the dark. The acetates were then analyzed by a gas chromatograph-mass spectrometer (GC-MS; Agilent HP 5971 Series GC-MSD, Agilent Technologies, Santa Clara, CA, USA). Analytical conditions were as follows: ionization method, El; ionization temperature, $280^{\circ} \mathrm{C}$; injection pot temperature, $250^{\circ} \mathrm{C}$; carrier gas, He (flow rate, 1.8 $\mathrm{mL} / \mathrm{min}$ ); $\mathrm{m} / \mathrm{z}$ range; 40 or 50 - 650; column, (DB-1 (15 m x $0.25 \mathrm{~mm}$, I.D., $0.25 \mu \mathrm{m}$ film thickness, Agilent Technologies; column temperature, $100^{\circ} \mathrm{C}(1 \mathrm{~min})-250^{\circ} \mathrm{C}\left(5^{\circ} \mathrm{C} / \mathrm{min}, 35 \mathrm{~min}\right)$. Catabolites were identified by comparing their retention times and mass spectra with those of the corresponding standards.

Genome sequencing and bioinformatics analysis. For genome sequencing analysis, mycelia of $I$. obliquus were cultured in $250 \mathrm{~mL}$ of potato-dextrose-broth (PDB; Becton, Dickinson and Company) medium (24 g/L (w/v)) under agitation at $100 \mathrm{rpm}$ with a shaker (NR-150; TAITEC Corp., Saitama, Japan) for 2 weeks at $25 \pm 2^{\circ} \mathrm{C}$ in the dark. After culture, the fungal mycelia in PDB medium were collected by filtration through a $0.22 \mu \mathrm{m}$-membrane filter (Tullagreen, Corrigtwohill, Co., Cork, Ireland). The experiments for extraction, library preparation, sequencing, and assembly of genomic DNA from this fungus were described previously ${ }^{45}$.

Prediction of transfer RNA (tRNA) and ribosomal RNA (rRNA) genes of the assembled genome sequence was conducted by performing searches on tRNAscan-SE ver. 1.3.1 ${ }^{46}$ and RNAmmer ver. $1.2^{47}$, 
respectively. Specifically, the tRNA genes were searched using the " -0 " option, and the obtained pseudo tRNA genes were eliminated. Protein coding genes were predicted by Augustus ver. 3.0.3 ${ }^{48}$ with the option '-species= phanerochaete_chrysosporium', and GeneMark-ES ${ }^{49}$. Then, predicted protein coding genes were annotated using several functional annotations based on homologous sequences. The predicted protein coding genes were searched using BLAST ${ }^{50}$, i.e. BLASTn and BLASTp. Searches using the BLASTn program against the non-redundant nucleotide database 'nt' and the BLASTp program against the protein database 'Swiss-prot' were applied with a threshold e-value of $1 \mathrm{E}^{-50}$. The predicted protein coding genes were also mapped onto functional annotations, including Pfam (Protein families), GO (Gene Ontology), and KEGG (Kyoto Encyclopedia of Genes and Genomes). InterProScan ${ }^{51}$ was used to predict Pfam and search GO, while the KEGG was searched using BlastKOALA ${ }^{52}$.

Cloning of a putative VP gene. The fungal mycelia were inoculated to Kirk medium ${ }^{40}$, incubated for 2 weeks and treated with veratryl alcohol as well as oxygen for 2 days under the same conditions described in section of enzyme activity essays. The fungal mycelia were then collected and the total RNA was isolated using TRIzol ${ }^{\mathrm{TM}}$ reagent (Thermo Fisher Scientific, Waltham, MA, USA). RNA quality was assessed using electrophoresis on $1 \%$ agarose gel, and its quantity was measured using a Nanodrop spectrophotometer (Thermo Fisher Scientific). One of seven putative VP genes obtained from the genome sequence (Gene ID: g1427.t1) was synthesized as cDNA using reverse transcription polymerase chain reaction (RT-PCR). Total RNA was used for 1st-strand cDNA synthesis with an oligo (dT) primer and PrimeScript RT Reagent Kit according to the manufacturer's guidelines (Takara Bio Inc., Shiga, Japan). The cDNA synthesis was performed as follows: 15 min reverse transcription reaction at $37^{\circ} \mathrm{C}, 5 \mathrm{~s}$ inactivation reverse transcription at $85^{\circ} \mathrm{C}$, and final reaction at $4^{\circ} \mathrm{C}$. Synthesized cDNA was then amplified with Ex Taq DNA Polymerase (Takara Bio Inc.) using the pair of specific primers (5'ATGTCTTTCGTTAAACTCCTTG-3' and 5'-TTACGGGTCCTTTAGTTTGTC-3') with thermal cycle parameters as follows: $1 \mathrm{~min}$ initial denaturation at $95^{\circ} \mathrm{C}, 34$ cycles of $30 \mathrm{~s}$ denaturation at $95^{\circ} \mathrm{C}, 30 \mathrm{~s}$ annealing at $65^{\circ} \mathrm{C}, 2$ min extension at $72^{\circ} \mathrm{C}$, and $5 \mathrm{~min}$ final extension at $12^{\circ} \mathrm{C}$. The pairs of specific primers were designed based on the predicted nucleotide sequence from genome sequence of $I$. obliquus. The amplified cDNAs were applied to electrophoresis on 1.5\% agarose gel and the PCR products were purified from the gel using FastGene® Gel/PCR Extraction Kit (Nippon Genetics Co., Ltd., Tokyo, Japan) and cloned in a pMD20-T vector using Mighty TA Cloning Kit (Takara Bio Inc.) according to the respective manufacturer's guidelines. The cDNA clones were isolated from bacterial cultures using a HiYield ${ }^{\mathrm{TM}}$ Plasmid Mini Kit (RBC Bioscience Corp., Taipei, Taiwan) and sequenced by Macrogen (Seoul, South Korea). Signal peptides were predicted in the deduced amino acid sequence using signalP-5.0 server. The obtained cDNA clone of putative VP in I. obliquus was then referred to as IO-PX.

Structural and phylogenetic analysis of IO-Px. Multiple alignment of the deduced amino acid sequence of IO-Px with other VPs were prepared using ClustalX software. The secondary structure of IO-Px was predicted by PSIPRED v3.3 on the PSIPRED server ${ }^{53}$. The protein structure of IO-Px was then modeled using the Swiss-Model automated protein structure homology-modeling server ${ }^{54}$ with templates from the Protein Data Bank (PDB) entries, 2BOQ, 1MnP, and Lga1 for VP, MnP, and LiP, respectively. 
Phylogenetic analysis using the deduced amino acid sequences of 57 basidiomycete peroxidases was performed using Geneious ver. 9. $1^{55}$. A list of the 57 basidiomycete peroxidases used in this study is shown in Supplementary Table 3. The concatenated amino acid sequences were aligned using the MAFFT alignment software ver. 1.4.0 56 . The phylogenetic analysis was conducted using the neighborjoining method $^{57}$.

\section{Declarations}

Data availability. The raw sequencing data were deposited at DNA Data Bank of Japan (DDBJ) as a DDBJ Sequence Read Archive (DRA) under the accession no. DRA008573, and the assembled contig data were deposited at DDBJ as a Bioproject under the accession no. PRJDB8445.

\section{Acknowledgements}

The authors thank Prof. Yoichi Honda, Graduate School of Agriculture, Kyoto University, for his valuable discussion of the amino acid sequence and steric structure of IO-PX.

This research was partially supported by the research grant for the UU-COE from Utsunomiya University (http://www.utsunomiya-u.ac.jp/en/index.php) to F. I., T. S. and S. Y., and by a Grant-in-Aid from JSPS KAKENHI (No. 17K07833) to T. S. and S. Y. This work was also supported by a Grant-in-Aid for Scientific Research on Innovative Areas “Frontier Research on Chemical Communications” (No. 17H06402) to T. S.

\section{Author contributions}

T.S. and S.Y. conceived the project and designed the experiment. R.A., T.S., I.N., . and H. A. performed the experiments. R.A., T.S., A. O., L.N., Y.T., H.A., and F.I. analyzed the data. R.A., T.S., and S. Y. wrote the manuscript. All authors critically reviewed the manuscript and approved the final version to be published.

\section{Competing interests}

The authors declare no competing interests.

\section{References}

1. Blanchette, R. A. Progressive stages of discoloration and decay associated with the Canker-Rot Fungus, Inonotus obliquus, in Birch. Phytopathology, 72, 1272-1277 (1982).

2. Lee, M. et al. Introduction to distribution and ecology of sterile conks of Inonotus obliquus., 36, 199202 (2008).

3. Zhong, X. H., Ren, K., Lu, S. J., Yang, S. Y. \& Sun, D. Z. Progress of research on Inonotus obliquus. Chin. J. Integr. Med, 15, 156-160 (2009).

4. Shashkina, M. Y., Shashkin, P. N. \& Sergeev, A. V. Chemical and medicobiological properties of chaga (review). Pharm. Chem. J, 40, 37-44 (2006). 
5. Manavalan, T., Manavalan, A. \& Heese, K. Characterization of lignocellulolytic enzymes from whiterot fungi. Curr. Microbiol, 70, 485-498 (2015).

6. Chen, H., Yan, M., Zhu, J. \& Xu, X. Enhancement of exo-polysaccharide production and antioxidant activity in submerged cultures of Inonotus obliquus by lignocellulose decomposition. J. Ind. Microbiol. Biotechnol, 38, 291-298 (2011).

7. Xu, X., Hu, Y. \& Quan, L. Production of bioactive polysaccharides by Inonotus obliquus under submerged fermentation supplemented with lignocellulosic biomass and their antioxidant activity. Bioprocess Biosyst. Eng, 37, 2483-2492 (2014).

8. Xu, X., Xu, Z., Shi, S. \& Lin, M. Lignocellulose degradation patterns, structural changes, and enzyme secretion by Inonotus obliquus on straw biomass under submerged fermentation. Bioresour. Technol, 241, 415-423 (2017).

9. Chi, Y., Hatakka, A. \& Maijala, P. Can co-culturing of two white-rot fungi increase lignin degradation and the production of lignin-degrading enzymes? Int. Biodeterior. Biodegrad, 59, 32-39 (2007).

10. Janusz, G. et al. Lignin degradation: microorganisms, enzymes involved, genomes analysis and evolution. FEMS Microbiol. Rev, 41, 941-962 (2017).

11. Eggert, C., Temp, U., Dean, J. F. D. \& Eriksson, K. E. L. A fungal metabolite mediates degradation of non-phenolic lignin structures and synthetic lignin by laccase. FEBS Lett, 391, 144-148 (1996).

12. Burton, S. G. Oxidizing enzymes as biocatalysts. TRENDS Biotechnol, 21, 543-549 (2003).

13. Sundaramoorthy, M., Kishi, K., Gold, M. H. \& Poulos, T. L. The crystal structure of manganese peroxidase from Phanerochaete chrysosporium at 2.06-Å resolution. J. Biol. Chem, 269, 3275932767 (1994).

14. Choinowski, T., Blodig, W., Winterhalter, K. H. \& Piontek, K. The crystal structure of lignin peroxidase at $1.70 \AA$ A resolution reveals a hydroxy group on the $C \beta$ of tryptophan 171: A novel radical site formed during the redox cycle. J. Mol. Biol, 286, 809-827 (1999).

15. Ruiz-Dueñas, F. J., Martínez, M. J. \& Martínez, A. T. Molecular characterization of a novel peroxidase isolated from the ligninolytic fungus Pleurotus eryngii. Mol. Microbiol, 31, 223-235 (1999).

16. Camarero, S., Sarkar, S., Ruiz-Dueñas, F. J., Martínez, M. J. \& Martínez, Ã. T. Description of a versatile peroxidase involved in the natural degradation of lignin that has both manganese peroxidase and lignin peroxidase substrate interaction sites*. J. Biol. Chem, 274, 10324-10330 (1999).

17. Ravichandran, A. \& Sridhar, M. Versatile Peroxidases: super peroxidases with potential biotechnological applications-a mini review. J. Dairy, Vet. Anim. Res, 4, 277-280 (2016).

18. Ohm, R. A. et al. Genomics of wood-degrading fungi. Fungal Genet. Biol, 72, 82-90 (2014).

19. Olson, Ã. et al. Insight into trade-off between wood decay and parasitism from the genome of a fungal forest pathogen. New Phytol, 194, 1001-1013 (2012).

20. Liu, D. et al. The genome of Ganderma lucidum provide insights into triterpense biosynthesis and wood degradation. PLoS One, 7, e36146 (2012). 
21. Floudas, D. et al. The paleozoic origin of enzymatic lignin decomposition reconstructedfrom 31 fungal genomes. Science (80-), 336, 1715-1719 (2012).

22. Chen, L. et al. Genome sequence of the edible cultivated mushroom Lentinula edodes (shiitake) reveals insights into lignocellulose degradation. PLoS One, 11, 1-20 (2016).

23. Li, H. et al. The Genome Sequences of 90 Mushrooms. Sci. Rep, 8, 6-10 (2018).

24. Janusz, G. et al. Fungal laccase, manganese peroxidase and lignin peroxidase: Gene expression and regulation. Enzyme Microb. Technol, 52, 1-12 (2013).

25. Martinez, A. T. Molecular biology and structure-function of lignin-degrading heme peroxidases. Enzyme Microb. Technol, 30, 425-444 (2002).

26. Ruiz-Dueñas, F. J. et al. Substrate oxidation sites in versatile peroxidase and other basidiomycete peroxidases. J. Exp. Bot, 60, 441-452 (2009).

27. Schüttmann, I. et al. Induction, characterization, and heterologous expression of a carotenoid degrading versatile peroxidase from Pleurotus sapidus. J. Mol. Catal. B Enzym, 103, 79-84 (2014).

28. Moreira, P. R. et al. Molecular characterisation of a versatile peroxidase from a Bjerkandera strain. J. Biotechnol, 118, 339-352 (2005).

29. Mohorčič, M., Benčina, M., Friedrich, J. \& Jerala, R. Expression of soluble versatile peroxidase of Bjerkandera adusta in Escherichia coli. Bioresour. Technol, 100, 851-858 (2009).

30. Mohanta, T. K. \& Bae, H. The diversity of fungal genome. Biol. Proced. Online, 17, 1-9 (2015).

31. Saar, M. Fungi in Khanty folk medicine. J. Ethnopharmacol, 31, 175-179 (1991).

32. Shin, Y. \& Tamai, Y. M. T. Chemical Constituents of Inonotus obliquus I. - A new triterpene, 3ß-hydroxy8,24-dien-lanosta-21,23-lactone from sclerotium -. Eurasian J. For. Res, 1, 43-50 (2000).

33. Yakovlev, I. A. et al. Genes associated with lignin degradation in the polyphagous white-rot pathogen Heterobasidion irregulare show substrate-specific regulation. Fungal Genet. Biol, 56, 17-24 (2013).

34. Eisenman, H. C. \& Casadevall, A. Synthesis and assembly of fungal melanin. Appl. Microbiol. Biotechnol, 93, 931-940 (2012).

35. Johjima, T., Ohkuma, M. \& Kudo, T. Isolation and cDNA cloning of novel hydrogen peroxidedependent phenol oxidase from the basidiomycete Termitomyces albuminosus. Appl. Microbiol. Biotechnol, 61, 220-225 (2003).

36. Liers, C., Bobeth, C., Pecyna, M., Ullrich, R. \& Hofrichter, M. DyP-like peroxidases of the jelly fungus Auricularia auricula-judae oxidize nonphenolic lignin model compounds and high-redox potential dyes. Appl. Microbiol. Biotechnol, 85, 1869-1879 (2010).

37. Linde, D. et al. Catalytic surface radical in dye-decolorizing peroxidase: A computational, spectroscopic and site-directed mutagenesis study. Biochem. J, 466, 253-262 (2015).

38. Henriksson, G. et al. Is cellobiose dehydrogenase from Phanerochaete chrysosporium a lignin degrading enzyme? Biochim. Biophys. Acta - Protein Struct. Mol. Enzymol, 1480, 83-91 (2000).

39. Pease, E. A., Andrawis, A. \& Tien, M. Manganese-dependent peroxidase from Phanerochaete chrysosporium. Primary structure deduced from cDNA sequence. J. Biol. Chem, 264, 13531-13535 
(1989).

40. Kirk, T. K., Croan, S., Tien, M., Murtagh, K. E. \& Farrell, R. L. Production of multiple ligninases by Phanerochaete chrysosporium: effect of selected growth conditions and use of a mutant strain. Enzyme Microb. Technol, 8, 27-32 (1986).

41. Leonowicz, A. \& Gzrywnowicz, K. Quantitative estimation of laccase forms in some white-rot fungi using syringaldazine as a substrate. Enzyme Microb. Technol, 3, 55-58 (1981).

42. Paszczynski, A., Huynh, V. B. \& Crawford, R. Enzymatic activities of an extracellular, manganesedependent peroxidase from Phanerochaete chrysosporium. FEMS Microbiol. Lett, 29, 37-41 (1985).

43. Tien, M. \& Kirk, T. K. Lignin-degrading enzyme from Phanerochaete chrysosporium: Purification, characterization, and catalytic properties of a unique H2O2-requiring oxygenase. Proc. Natl. Acad. Sci. 81, 2280-2284(1984).

44. Yokota, S. \& Umezawa, T. T. H. No Influence of alkoxyl ring substituents on the degradability of betaortho-4 lignin substructure model dimers by Phanerochaete chrysosporium. J. Japan Wood Res. Soc, 34, 65-74 (1988).

45. Agnestisia, R. et al. The complete mitochondrial genome sequence of the medicinal fungus Inonotus obliquus (Hymenochaetaceae, Basidiomycota). Mitochondrial DNA Part B Resour, 4, 3504-3506 (2019).

46. Schattner, P., Brooks, A. N. \& Lowe, T. M. The tRNAscan-SE, snoscan and snoGPS web servers for the detection of tRNAs and snoRNAs. Nucleic Acids Res, 33, 686-689 (2005).

47. Lagesen, K. et al. RNAmmer: consistent and rapid annotation of ribosomal RNA genes. Nucleic Acids Res, 35, 3100-3108 (2007).

48. Stanke, M., Diekhans, M., Baertsch, R. \& Haussler, D. Using native and syntenically mapped cDNA alignments to improve de novo gene finding., 24, 637-644 (2008).

49. Ter-Hovhannisyan, V., Lomsadze, A., Chernoff, Y. O. \& Borodovsky, M. Gene prediction in novel fungal genomes using an ab initio algorithm with unsupervised training. Genome Res, 18, 1979-1990 (2008).

50. Altschul, S. F., Gisg, W. A. R. R. E. N., Miller, Webb, Myers, E. W. \& Lipman, D. J. Basic local alignment search tool. J. Mol. Biol, 215, 403-410 (1990).

51. Quevillon, E. et al. InterProScan: Protein domains identifier. Nucleic Acids Res, 33, 116-120 (2005).

52. Kanehisa, M., Sato, Y. \& Morishima, K. BlastKOALA and GhostKOALA: KEGG Tools for Functional Characterization of Genome and Metagenome Sequences. J. Mol. Biol, 428, 726-731 (2016).

53. Buchan, D. W. A., Minneci, F., Nugent, T. C. O., Bryson, K. \& Jones, D. T. Scalable web services for the PSIPRED Protein Analysis Workbench. Nucleic Acids Res, 41, 349-357 (2013).

54. Biasini, M. et al. SWISS-MODEL: Modelling protein tertiary and quaternary structure using evolutionary information. Nucleic Acids Res, 42, 252-258 (2014).

55. Kearse, M. et al. Geneious Basic: An integrated and extendable desktop software platform for the organization and analysis of sequence data., 28, 1647-1649 (2012). 
56. Katoh, K., Misawa, K., Kuma, K. I. \& Miyata, T. MAFFT: A novel method for rapid multiple sequence alignment based on fast Fourier transform. Nucleic Acids Res, 30, 3059-3066 (2002).

57. Naruya Saitou \& Masatoshi Nei. The Neighbor-joining Method: A new method for reconstructing phylogenetic trees. Molecular Biology and Evolution, 4, 406-425 (1987).

\section{Figures}
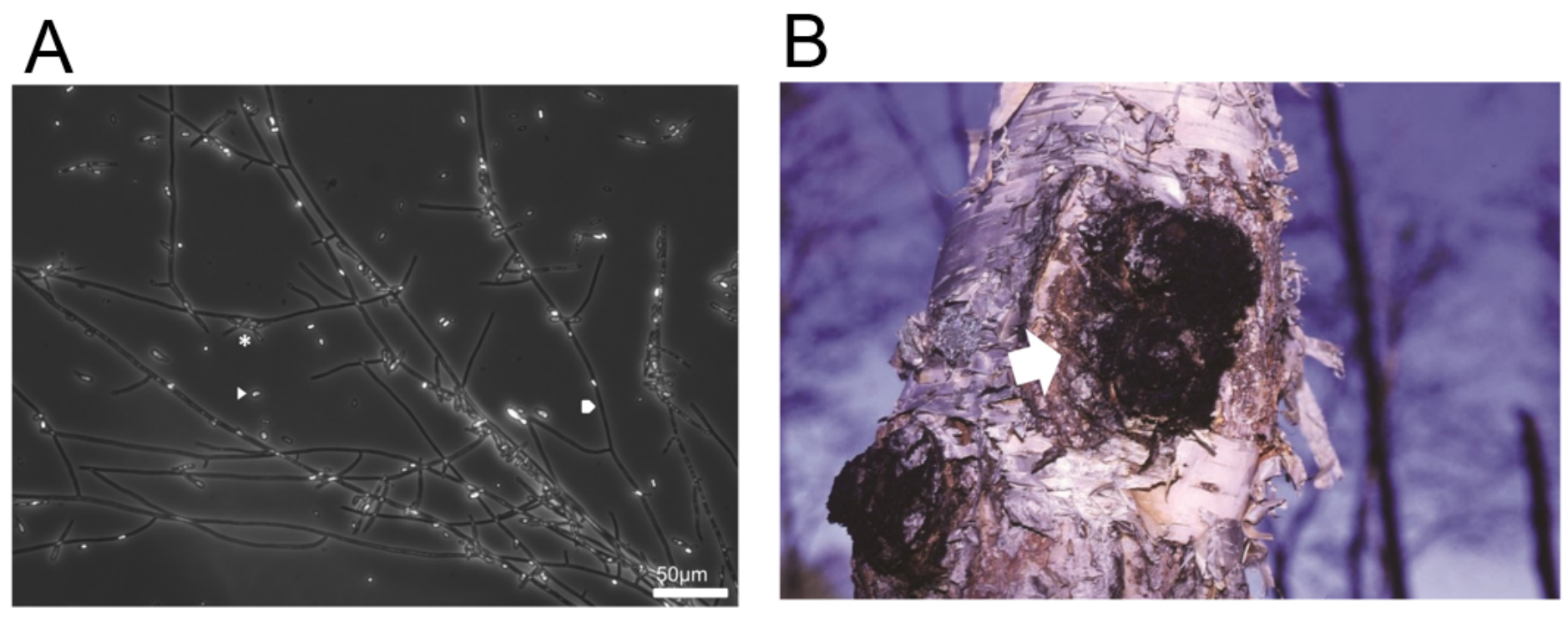

\section{Figure 1}

White-rot fungus I. obliquus. (A) Micrograph of I. obliquus mycelia obtained by phase-contrast microscopy. Pentagon and arrowhead indicate mycelium and conidium, respectively. In this case, I. obliquus mycelia are still germinating (asterisk). Scale bar, $50 \mu \mathrm{m}$. (B) Photograph of I. obliquus sclerotium (white arrow) on a Japanese birch tree. The photograph was taken by Shinso Yokota.<smiles>CCOc1ccc(C(O)C(CO)Oc2c(OC)cccc2OC)cc1OC</smiles>

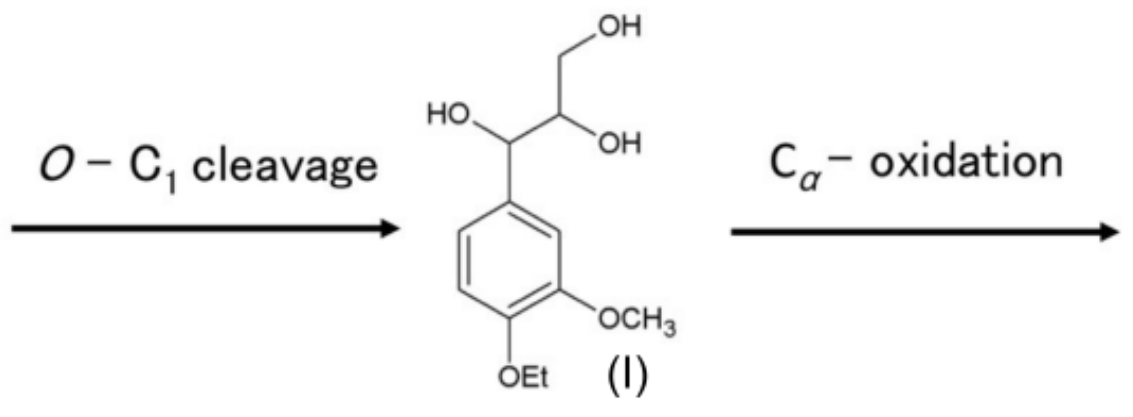<smiles>CCOc1ccc(C(=O)C(O)CO)cc1OC</smiles>

\section{Figure 2}

Potential degradation pathway of lignin model dimer by I. obliquus. 


$10^{\circ}$

20

30

40

$50^{\circ}$
PC-MnP
IO-VP
B-VP
PE-VPL
PE-VPL
PE-VPL
PE-VPS
PSA-VP
PO-MnP
PO-MnP
PP-MnP

PC-LiPA $70^{\circ}$ $80^{\circ}$
.1 $\ldots 1 \ldots 1$

100 MAFKSLIAFV ALAAAVRAAP -------- TAVCPDGT-R VSHAACCAFI PLAQDLQETI FQN-ECGEDA HEVIRLTFHD AIAISRSQGP K---AGGGAD MSFVKLLA-F TSVAATFSGA YAALT----R RATCPDGVNT ATNAACCSWF AVRDDLQNNL FSN-ECGEEV REALRLTFHD GIAFSPTLG- -----GGGAD MAFKOLLTAA LSIALALPFS OAAIT----R RVACPDGVNT ATNAACCALF AVRDDIQQNL FDGGECGEEV HESLRLTFHD AIGISPSLAA TGKFGGGGAD MSFKTLSALA LALGAAVQFA SAAVP-LVQK RATCADGR-T TANAACCVLF PILDDIQENL FDGAQCGEEV HESLRLTFHD AIGFSPTLG- -----GGGAD MSFKTLSALA LALGAAVQFA SAAVP-LVQK RATCDDGR-T TANAACCILF PILDDIQENL FDGAQCGEEV HESLRLTFHD AIGFSPTLG- -----GGGAD MSFKTLSALA LALGAAVQFA SAAVP-LVQR RATCADGR-T TANAACCVLF PILDDIQENL FDGAQCGEEV HESLRLTFHD AIGFSPTLG- ------GGGAD MAFAKLSAFV LALGATVALG ESPTHRCLNK RVTCATGQ-T TANEACCALF PILDDIQTNL FDGAQCGEEV HESLRLTFHD AIAFSPALTN AGQFGGGGAD MSFKTLSALV LALGAAVQFT SAAVP-RVQK RATCADGR-T TANAACCVLF PILDDIQENL FDGGQCGEEV HESLRLTFHD AIGFSPTLG- ------GGGAD MTFASLSALV LVFAVTVQVA -QAVS-LPQR RATCAGGQ-V TANAACCVLF PLMEDLQKNL FDDGACGEDA HEALRLTFHD AIGFSPSRGV -----MGGAD MAFAKLSALV LALGATVALG AP----SLNK RVTCATGQ-T TANEACCALF PILEDIQTNL FDGAQCGEEV HESLRLTFHD AIAFSPALTN AGQFGGGGAD MTIASLSALV LAFAATVQVA -QAVS-LPOK RATCAGGQ-V TANAACCVLF PLMEDLQKNL FDDGACGEDA HEALRLTFHD AIGFSPSRGV ------MGGAD MAFKQLFA-A ISLALLLSAA NAAAV--IEK RATCSNGK-T VGDASCCAWF DVLDDIQQNL FHGGQCG

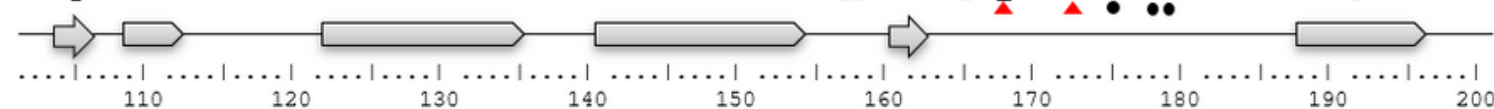
PC-MnP1 GSMLLFPTVE PNFSANNG-- -IDDSVNNLI PFMQRHNTIS AADLVQFAGA VALSNCPGAP R-LEFLAGRP NKTIAAVDGL IPEPQDSVTK ILQRFEDAGG IO-VP

PE-VPL1 PE-VPL2 PE-VPL3 GSIITFADTE LTFAANGGNG GVDDIVNTLT PFVSKWN-VT PGDLIYFASS VGTSNCPGAP R-LQFFAGRP NPVAAAPDGL VSQPGDSVDT ILARFADAGGSIMIFDDIE PNFHANNG-- -VDEIINAQR PFVARHN-MT AGDFIQFAGA VGVSNCPGAP Q-LSFFLGRP AATQPAPDGL VPEPFDSVTD ILNRFADAGG GSIIAFDTIE TNFPANAG-- -IDEIVSAQR PFVAKHN-IS AGDFIQFAGA VGVSNCPGGV R-IPFFLGRP DAVAASPDHL VPEPFDSVDS ILARMSDAGGSIIAFDTIE TNFPANAG-- -IDEIVSAQR PFVAKHN-IS AGDFIQFAGA VGVSNCPGGV R-IPFFLGRP DAVAASPDHL VPEPFDSVDS ILARMGDAGGSIIAFDTIE TNFPANAG-- -IDEIVSAQR PFVARHN-IS AGDFIQFAGA VGVSNCPGGV R-IPFFLGRP DAVAASPDHL VPEPFDSVDT ILARMGDAGGSMIIFSDTE PNFHANLG-- -IDEIVEAQR PFIARHN-IS AADFIQFAGA IGVSNCAGAP R-LNFFLGRP DATQIPPDGL VPEPFDDVTR ILSRMGDAGGSIITFDTIE TVFPANAG-- -IDEIVSAQR PFVARHN-IS AGDFIQFAGA VGVSNCPGGV R-IPFFLGRP DAVAASPDHL VPEPFDSVDT ILARMGDAGGSVITFSDTE VNFPANLG-- -IDEIVEAER PFLARHN-IS AGDLVHFAGT LAVTNCPGAP R-IPFFLGRP PARAASPIGL VPEPFDTITD ILARMDDAGGSMIIFSDTE PNFHANLG-- -IDEIVEAQR PFIARHN-IS AADFIQFAGA IGVTNCAGAP R-LNFFLGRP DATQIPPDGL VPEPFDSVDR ILSRMGDAGGSVITFSDTE VNFPANLG-- -IDEIVEAER PFLARHN-IS AGDLVHFAGT LGVSNCPGAP QNLSFFLGRP PARAASPIGL VPEPFDTITD ILARMDDAGGSIMIFDDIE TAFHPNIG-- -LDEIVKLQR PFVQRHG-VT PGDFIAFAGA VALSNCPGAP Q-MNFFTGRA PATQPAPDGL VPEPFHTVDQ IINRVNDAGE

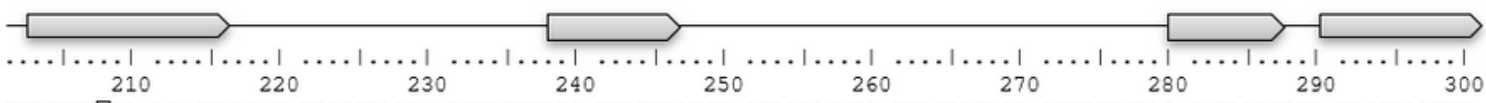

PC-MnP1 FTPFEVVISLL ASHSVARADK VDQTIDAAPF DSTPFTFDTQ VFLEVLLRGV GFPGSANNTG EVASPLPLGS GSDTGEMRLQ SDFALAHDPR TACIWQGFVN IO-VP

IO-VP

PE-VPL1

PE-VPL2

PE-VPL3

PE-VPS1

PSA-VP

PO-MnP1

PO-MnP2

PP-MnP5

PC-LiPA

FSSDEVW FTIQEVVWLI ASHSIAAADH VDPTIPGSPF DSTPEIFDTQ FFVETLLKGT LFPGTSGNQG EVESPLAG-- -----EIRLQ SDADFARDSR TACEWQSFVN FSPVEVWWL ASHSIAAADK VDPSIPGTPF DSTPGVFDSQ FFIETQLKGR LFPGTADNKG EAQSPLQG-- -----EIRLQ SDHLLARDPQ TACEWQSMVN FSPVEVWWL ASHSIAAADK VDPSIPGTPF DSTPGVFDSQ FFIETQLKGR LFPGTADNKG EAQSPLQG-- -----EIRLQ SDHLLARDPQ TACEWQSMVN FSPVEVVWLI ASHSIAAADK VDPSIPGTPF DSTPGVFDSQ FFIETQLKGK LFPGTADNKG EAQSPLQG-- -----EIRLQ SDHLLARDPQ TACEWQSMVN FSTVEVVWLL ASHTIAAADH VDPSIPGTPF DSTPSTFDSQ FFLETMLQGT AFPGTPGNQG EVESPLAG-- -----EMRLQ SDFLLARDSR SACEWQSMVN FSAVEVVWLI ASHSIAAADL VDPSIPGTPF DSTPGVFSQ FFIETQLKGR LFPGTPDNKG EVQSPLQG-- ------EIRLQ SDHLLARDPQ TACEWQSMVN FVSVEVWWL SAHSVAAADH VDETIPGTPF DSTPNLFDSQ IFIETQLRGI SFPGTGGNHG EVQSPLRG-- -----EMRLQ SDHLFARDDR TSCEWQSMTN FSTVEVVWLL SSHTIAAADL VDPSIPGTPF DSTPSTFDSQ FFLETMLQGT AFPGTPGNQG EVESPLAG-- -----EMRLQ SDFLLARDSR SACEWQSMVN FVSVEVVWLI SAHSVAAADH VDESIPGTPF DSTPNLFDSQ IFIETQLRGI SFPGTGGNHG EVQSPLRG-- -----EMRLQ SDHLFARDDR TSCEWQSMTN FDELELVWML SAHSVAAVID VDPTVQGLPF DSTPGIFDSQ FFVETQLRGT AFPGSGGNQG EVESPLPG-- ----EIRIQ SDHTIARDSR TACEWQSFVN

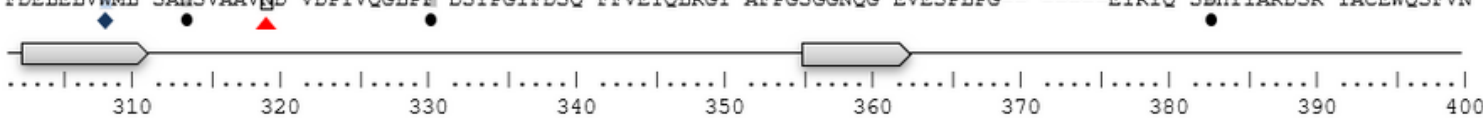
PC-MnP1 EQAFMAASFR AAMSKLAVLG HNRNSIIDCS DVVPVPK--- PATGQPAMFP ASTGPQDLEL SC--PSERFP TLTTQPGASQ SLIAHCPDGS MSCPGVQFNG IO-VP 10-VP PE-VPL1 PE-VPL2 PE-VPL3 DQDGMRSAFA AVMTKLSLLG Q-PSNLIDCT EVIGQPPAAP VGDGAAPYFP GADTVTDVIS AC--TATPFP TLTQNP-AVT SLVS-VKEN-

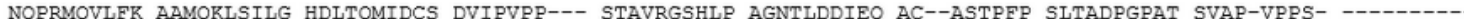
NQPKIQNRFA ATMSKMALLG QDKTKLIDCS DVIPTP---- PALVGAAHLP AGFSLSDVEQ AC--AATPFP ALTADPGPVT SVPP-VPGS- ----------NQRKIQNRFA ATMSKMALIG QDKTKLIDCS DVIPTP---- PALVGAAHLP AGFSLSDVEQ AC--AATPFP ALTADPGPVT SVPP-VPGS- ----------NQPKIQNRFA ATMSKMALLG QDKTKLIDCS DVIPTP---- PALVGAAHLP AGFSLSDVEQ AC--AETPFP ALTADPGPVT SVPP-VPGSNMPKIQNRET QVMKRLSLLG HNQADLIDCS DVIPVP---- KTLTKAATFP AGKSQADVEI VCNAAATPFP ALASDPGPVT AVPP-VPPSNQPKIQNRFA ATMSKMALLG QDKSKLIDCS DVIPTP---- PALVGAAHLP AGFSLSDVEQ AC--AETPFP ALTADPGPVT SVPP-VPGS- ----------DQQRIQDRFS DTLFKMSMLG QNQDAMIDCS DVIPVP---- AALVTKPHLP AGKSKTDVEQ AC--ATGAFP ALGADPGPVT SVPR-VPPA- ----------NMPKIONRFT OVMRKLSLIG HNOADLIDCS DVIPVP---- KTLTKAATFP AGKSOADVEI VV--AATPFP ALASDPGPVT AVPP-VPPS-

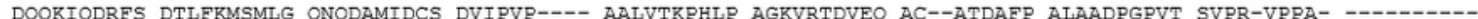
NQSKLVDDFQ FIFLALTQLG QDPNAMTDCS DVIPQSKPI- PGNLPFSFFP AGKTIKDVEQ AC--AETPFP TLTTLPGPET SVQR-IPPP- ---PGA----

helix $\quad \Rightarrow$ strand $\quad$ coil $\square$ not homology

Heme pocket residues $\Delta$ Mn-binding site $>$ Tryptophan

\section{Figure 3}

Multiple alignments of the deduced amino acid sequence of IO-Px. PC, Phanerochaete chrysosporium; IO, Inonotus obliquus; B, Bjerkandera sp.; PE, Pleurotus eryngii; PSA, P. sapidus; PO, P. ostreatus; PP, P. pulmonarius; $\mathrm{MnP}$, manganese peroxidase; $\mathrm{Px}$, putative versatile peroxidase; VP, versatile peroxidase; LiP, lignin peroxidase. The underlined amino acid sequence indicates the signal peptide. 

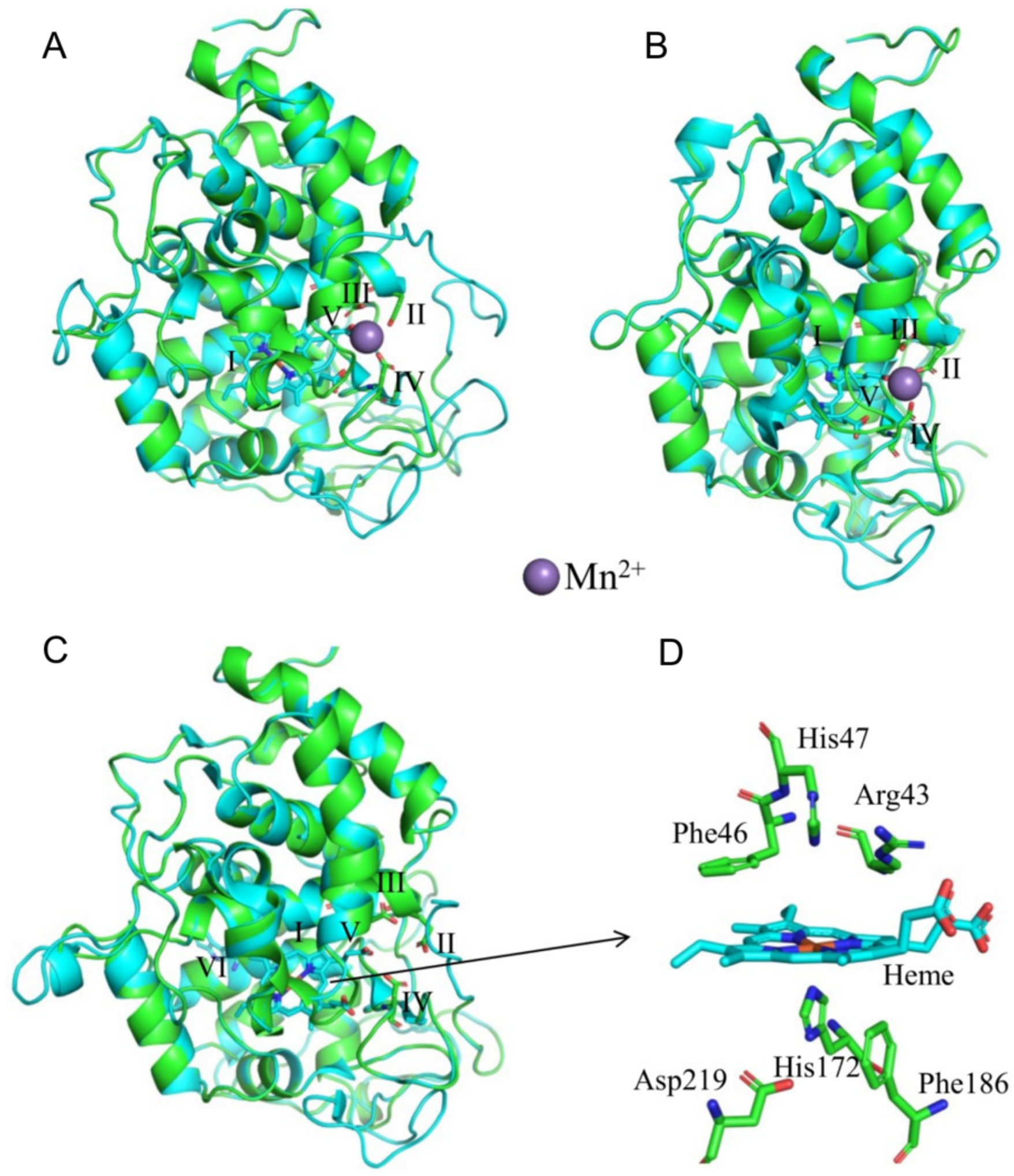

Figure 4

Molecular models and heme environment of IO-Px. The protein structure of IO-Px is represented in templates of the following PDB entries: (A) $1 \mathrm{MnP}$ for manganese peroxidase (MnP), (B) 2BOQ for versatile peroxidase (VP), and (C) Lga1 for lignin peroxidase (LiP); (D) heme environment of IO-Px from the three templates. I, heme cofactor; II, Glu36; III, Glu40; IV, Asp178; V, internal heme propionate; VI, Trp171 from 1MnP template. 


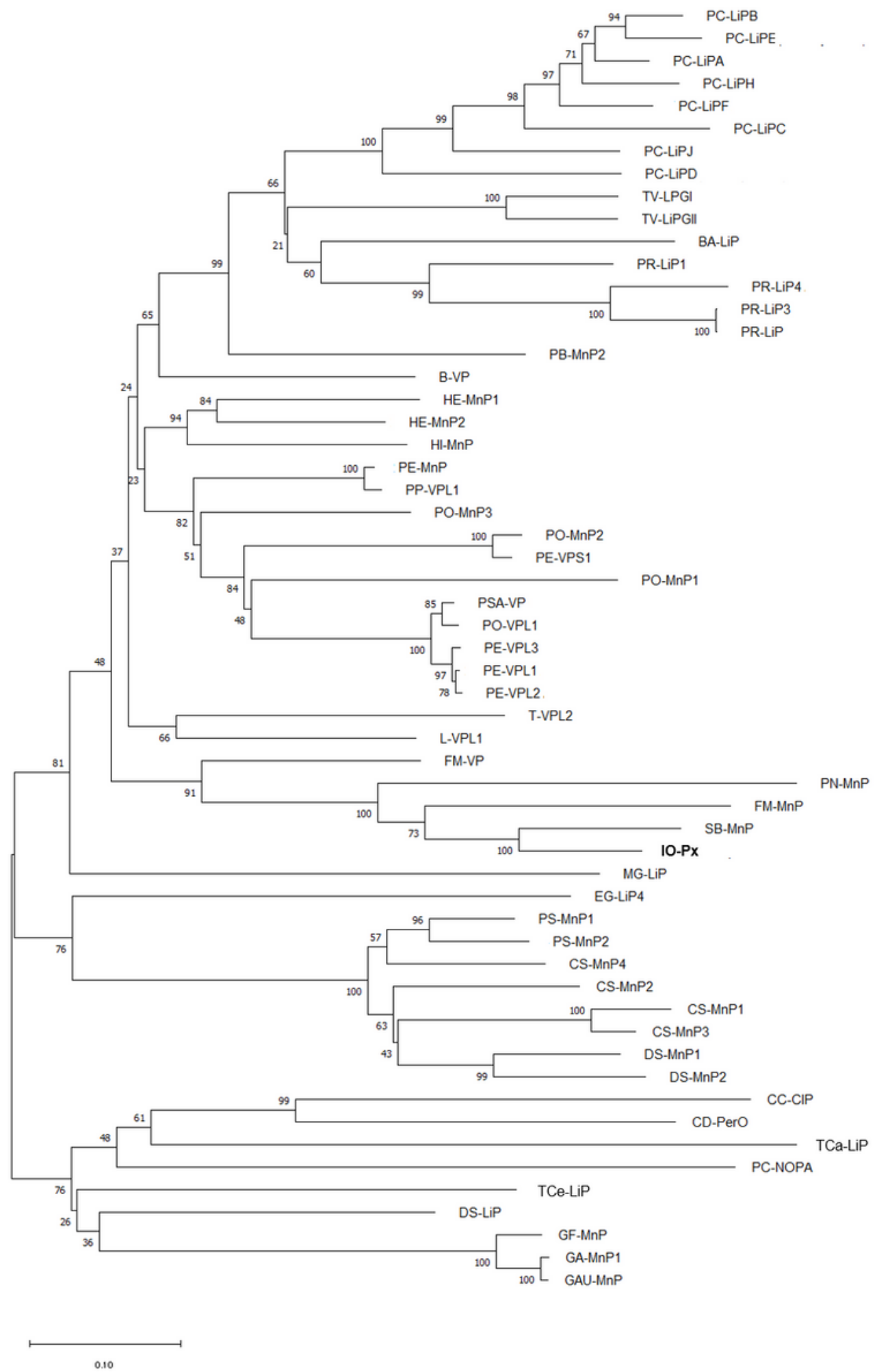

Figure 5

Molecular phylogenetic analysis of 57 genes encoding manganese peroxidases, versatile peroxidases, and lignin peroxidases. MnP, manganese peroxidase; VP, versatile peroxidase; LiP, lignin peroxidase; Px, putative versatile peroxidase. For other abbreviations refer to Supplementary Table 3.

\section{Supplementary Files}


This is a list of supplementary files associated with this preprint. Click to download.

- SupplementaryFigures211010RA.docx

- SupplementaryTable2211019RA.xIsx

- SupplementaryTables13211019RA.docx 